to draw the attention of the profession to the fact that gonococcal infection of the pharynx occurs, that the clinical condition is sometimes severe and, contrary to the find ings here, not always accompanied by genital infection, and also that our knowledge of the sexual practices of the population is scanty.-I am, etc.,

V.D. Department,

Birmingham

\section{Lithium and Weight Gain}

SIR,-Your leading article "Drugs Causing Weight Gain" (2 February, p. 168) mentions lithium carbonate taken over months in the prophylaxis of manic-depressive disorders. Patients on this treatment stay on lithium for years and the long-term considerations could be stressed. It has been shown that generally the weight gain with prophylactic lithium occurs in the first six months, and after this initial increase the weight remains constant for many years. There is also some, rather limited, evidence that this initial increase in weight represents solid weight rather than water and that it is probably a reversal of weight loss during recurrent psychiatric illnesses. ${ }^{2}$ Lithium, in a few cases, at the beginning of treatmen may cause increased drinking due to thirst It is helpful to advise patients against drinks containing sugar. ${ }^{3}$ One of the im portant factors causing patients, particularly women, to stop taking their lithium is a fear of an excessive increase in weight. Such lapse in treatment is not so likely if th: pattern of an initial gain to be followed by stabilization at a somewhat higher weight is explained to the patient and their relatives.

From a practical point of view when prescribing prophylactic lithium your advice about physical checks, which should include regular weighing, is very desirable. A patient's initial gain in weight followed by his maintaining a constant body weight with be generally reassuring. It would be ur fortunate if largely unnecessary short-term considerations by patients, their relatives, and their doctors during the first few months of prophylactic lithium caused the treatment to be stopped.-I am, etc., Northern General Hospital,
Sheffield

R. J. KERRY

1 Kerry, R. J., Liebling, L. I., and Owen, G. 2 Acta Psychiatrica Scandinavica, 1970, 46, 238. 2 Kerry, R. J., and Owen, G.,

3 Furlong, F. W., Canadian Psychiatric Association Fournal, 1973, 18, 75 .

\section{Attitudes to Abortion}

SIR,-You have been taken to task by a number of correspondents (4 May, p. 276 11 May, p. 329) concerning your leading article "Attitudes to Abortion" (13 April p. 69). They are mainly concerned with only one emotive aspect of the problem. There are others.

You say that "abortion ... is a poor substitute for contraception as a means of stopping unwanted births." This is indeed true, but so much of our work is concerned with the failures of preventive medicine and until we can eliminate the congenital defects in the newborn, abolish the stress diseases, control all infections, deal with the cause of dental decay, and find some cause for cancer we shall have to accept a situation that is not ideal. One day, I hope, all children will be conceived with the willing consent of both parents, but meanwhile the Abortion Act of 1967 does enable the medical profession to alleviate a very great deal of mental and physical suffering and to mitigate the results of the failure of methods of contraception that are admittedly imperfect.

It is suggested by Professor H. C. McLaren (12 May, p. 329) that one termination of pregnancy every three months is all that a consultant "practising modern obstetrics, offering compassion and advice" should be doing. This statement is, with respect, that of someone living in another world. A study of some of the carefully compiled case histories of those patients presenting themselves to such organizations as the British Pregnancy Advisory Service would enable a balanced judgement to be made.-I am, etc.,

Hove, Sussex

REX BINNING

SIR, -I am sure that there are many doctors who share my great anxiety for the future of gynaecological departments and even possibly for the Royal College of $\mathrm{Ob}$ stetricians and Gynaecologists itself if the Lane Report ${ }^{1}$ is accepted by the Government and implemented.

For doctors generally it would mean that there could be no prospect of specializing in gynaecology for Roman Catholics or for those who hold similar views on the subject of abortion. Inside the royal colleges it could create endless divisions among Fellows and members. For nurses it would perpetuate the atmosphere we have felt since the Act has been on the statute book-a reluctance on the part of many to work in the gynaecological wards and theatres. Finally for the patients too there would be an unacceptable paradox when a woman having a threatened miscarriage or being investigated for infertility is nursed alongside one having an abortion for reasons other than strictly medical ones.

Of course one can understand the desire to use the training and expertise of the gynaecologist to ensure "safe" abortions throughout the country, in which there is said to be a majority demand for such a service. But for job satisfaction on the part of doctors and nurses and for peace in the hospitals I am absolutely convinced that beds allocated for the purpose should be separate from the gynaecological ward and staffed by those who agree with this type of practice.

In other words, I suggest a new subspecialty-gynaecology (abortion).-I am, etc.,

\section{Croydon}

J. C. MILLER Report of the Committee on the Working of the
Abortion Act, Cmnd 5538. London, H.M.S.O.

SIR,-Prafessor H. C. Malaren (11 May, p. 329) is surely overstating his case when he tries to imply any parallel between the state atrocities of the Nazis and official recognition here of the reality of the need for abortion and the essentially humanitarian nature of the service it provides when abartion is inevitable.

Conscience must be seen to have its positive face. The "conscience clause" cannot be regarded as merely a negative one allowing only the right of abstention from helping the distressed. It also entitles those who are humanly concerned enough to wish to do so the right to ensure, within the law, proper medical help for those who would otherwise pass into the hands of the backstreet abortionists, with all the awful consequences of this that Professor McLaren and I, and all our generation, know very well. Hospital administrators have crtainly a right on behalf of the public to stand on the side of such a positive interpretation of the "conscience clause" and for the intention of the Abortion Act as law. Trying to cripple the working of the Act seems to me almost as unworthy as profiteering from it. Those, and particularly those like Professor McLaren, who have a long and wide experience in hospital wards of the distress, damage, and not infrequently death resulting from septic abortions performed outside and who, despite it, think as he appears to do perhaps have a need to unblinker the function of conscience to give it a wider and more human sweep.

The trouble is that our natural humanity is hedged about with doctrines. Once it was thought salutary to the soul to scourge the body or to torture to death in the name of religion. We have a need still to shed all such doctrines and let the human spirit shine through. Unfortunately, the old coin is still being offered by some today as if it was valid tender without question, though very many now doubt, with reason, that it is gold. Perhaps, in our profession today we have a need to apply the touchstone more courageously and more emphatically to such coin, whoever it is presents it.-I am, etc.,

London N.W.3

N. A. Chisholm

\section{Vaccination of Smallpox Contacts}

SIR,-In reply to Dr. D. J. Bauer's letter (23 March, p. 576) we would like to stress that we stated (17 November 1973, p. 423) that "it is generally accepted that successful vaccination within up to about 48 hours after exposure will usually protect contaots against smallpox." We do not consider that there is anything absolute in the effectiveness of smallpox vaccination, and its success depends on many factors.

The efficacy of vaccination following exposure could be accurately determined only by carefully controlled studies, but these will never be done because of the known effectiveness of the procedure, which could not be withheld from any exposed person.

We have again reviewed the references quoted by Dr. Bauer but cannot reconcile his table with the published data. In his table there is no indication whether "day of primary vaccination or revaccination" relates to the day of onset of illness or to the day of contact. Only in Hanna's book and the paper of Lyons and Dixon ${ }^{2}$ is it possible to deduce reasonably accurate information of the day of vaccination and the day of exposure. In the data of $\mathrm{Smith}^{3}$ and Cramb $\mathrm{b}^{4}$ the date of vaccination and the date of onset are stated and only an and the date of onset are stated and only an estimate of the day of vaccination in relation to contact can be made. Even so our analysis of the reason Dr. Bauer does not include the data from 